\title{
Double, Double Toil and Trouble
}

With the complete sequence of the human genome being available, systematic mapping of regions of transcription, transcription factor binding, chromatin structure and histone modification has revealed that $80 \%$ of the genome outside of the protein-coding regions performs essential biochemical functions [ENCODE, 2012]. The 'remainder' of the human genome contains repeat elements, such as LINEs, SINEs, alpha satellites, and low-copy repeats (LCRs), also known as segmental duplications [Ji et al., 2000; Bailey et al., 2002]. These LCRs are at least $1 \mathrm{kbp}$ in size, show more than $98 \%$ homology and predispose the intervening sequences to recombination. Such recombination events produce DNA copy number variations (CNVs), e.g. deletions and duplications, and inversions, which may manifest as genomic disorders [Sharp et al., 2006a]. Such genomic disorders occur with a frequency of $0.7-1.0$ per 1,000 live births, often share neurodevelopmental phenotypes and are detected by genome-wide segmental aneuploidy screening [Ji et al., 2000; Hochstenbach et al., 2009, 2011]. CNVs flanked by 2 LCRs are termed recurrent CNVs, since they occur relatively often in cohorts of patients with genomic disorders [Koolen et al., 2006; Sharp et al., 2006b; Mefford et al., 2008; Hannes et al., 2009]. However, since recurrent $\mathrm{CNV}$ also occur in healthy individuals, they themselves are not necessarily pathogenic [Poot et al., 2010]. Indeed, in some patients, 2 recurrent CNVs were found such that concomitant changes in the dosage of genes in both CNVs may account for the clinical phenotype [Girirajan et al.,
2010; Poot et al., 2010]. These findings may explain some of the phenotypic variability among patients with genomic disorders and prompted a 2-hit hypothesis for developmental disorders [Girirajan and Eichler, 2010; Girirajan et al., 2011; Poot et al., 2011].

A special class of rearrangements is located between inverted repeats (IRs), which may render $\sim 12 \%$ of the genome susceptible to formation of inversions or of complex duplication-inverted triplication-duplication (DUPTRP/INV-DUP) rearrangements. Fosmid paired-end sequencing has identified 224 nonredundant inversions in 8 human genomes that were not included in the human reference genome [Kidd et al., 2008]. Recently, IRs were shown to mediate (DUP-TRP/INV-DUP) rearrangements, including the MECP2 duplication syndrome (MIM 300260), Duchenne muscular dystrophy (MIM 310200), VIPR2 triplication, CHRNA7 triplication, and Pelizaeus-Merzbacher disease (MIM 312080) [Carvalho et al., 2011; Shimojima et al., 2012; Beri et al., 2013; Ishmukhametova et al., 2013; Soler-Alfonso et al., 2014]. Duplication of the X-linked proteolipid protein 1 (PLP1) gene is the major mutational cause for Pelizaeus-Merzbacher disease and explains $\sim 80 \%$ of the cases. This duplication occurs via a mechanism that results in a DUPTRP/INV-DUP structure [Carvalho et al., 2011; Beck et al., 2015]. An IR distal to PLP1 facilitates DUP-TRP/INVDUP formation as well as an inversion, a structural variation found frequently among healthy individuals. PLP1 duplications were detected in 10 patients with spastic

\section{KARGER 125}

() 2015 S. Karger AG, Base

$1661-8769 / 15 / 0063-0106 \$ 39.50 / 0$ 
paraplegia type 2 (MIM 312920), whereas triplications were detected in 6 patients [Beck et al., 2015]. STR markers for these duplicated/triplicated regions were monomorphic in 12 of the 13 patients tested. This indicates that in these patients a single allele was affected by intrachromosomal rearrangement events.

Analysis of the breakpoint junction sequences allows us to identify the underlying mutational process, such as fork stalling and template switching, microhomologymediated break repair (MMBIR), or a near homologous recombination event between similar Alu elements or LCRs [Hastings et al., 2009]. The nonrecurrent junctions in these patients were consistent with MMBIR [Beck et al., 2015]. This contention is supported by the observation of triplicated and quadruplicated segments, point mutations being associated with some of the breakpoint junctions, and the presence of intrachromosomal rearrangements [Carvalho et al., 2013; Beck et al., 2015]. Quadruplication and a potentially higher-order amplification of a genomic interval may have resulted from rolling-circle amplification of segments between IRs as predicted by the MMBIR model [Hastings et al., 2009]. The mechanisms for such complex genomic rearrangements have only begun to be elucidated, but the present study has contributed novel insights into this hitherto neglected type of genomic rearrangement [Hastings et al., 2009; Beck et al., 2015]. Although duplications, triplications, quadruplications, etc. do not emerge from the boiling cauldron of the witches in Shakespeare's Macbeth, there are more things in our genome than are dreamt of in our philosophy.

Martin Poot

\section{References}

Bailey JA, Gu Z, Clark RA, Reinert K, Samonte $\mathrm{RV}$, et al: Recent segmental duplications in the human genome. Science 297:1003-1007 (2002).

-Beck CR, Carvalho CM, Banser L, Gambin T, Stubbolo D, et al: Complex genomic rearrangements at the $P L P 1$ locus include triplication and quadruplication. PLoS Genet 11:e1005050 (2015).

Beri S, Bonaglia MC, Giorda R: Low-copy repeats at the human VIPR2 gene predispose to recurrent and nonrecurrent rearrangements. Eur J Hum Genet 21:757-761 (2013).

-Carvalho CM, Ramocki MB, Pehlivan D, Franco LM, Gonzaga-Jauregui C, et al: Inverted genomic segments and complex triplication rearrangements are mediated by inverted repeats in the human genome. Nat Genet 43: 1074-1081 (2011).

Carvalho CM, Pehlivan D, Ramocki MB, Fang P, Alleva B, et al: Replicative mechanisms for CNV formation are error prone. Nat Genet 45:1319-1326 (2013).

ENCODE Project Consortium: An integrated encyclopedia of DNA elements in the human genome. Nature 489:57-74 (2012).

Girirajan S, Eichler EE: Phenotypic variability and genetic susceptibility to genomic disorders. Hum Mol Genet 19:R176-R187 (2010).

-Girirajan S, Rosenfeld JA, Cooper GM, Antonacci F, Siswara P, et al: A recurrent 16p12.1 microdeletion supports a two-hit model for severe developmental delay. Nat Genet 42:203209 (2010).

-Girirajan S, Campbell CD, Eichler EE: Human copy number variation and complex genetic disease. Annu Rev Genet 45:203-226 (2011).
Hannes FD, Sharp AJ, Mefford HC, de Ravel T, Koolen DA, Vissers LE, Pfundt R, de Leeuw N, Ruivenkamp CA, et al: Recurrent reciprocal deletions and duplications of 16p13.11: the deletion is a risk factor for MR/MCA while the duplication may be a rare benign variant. J Med Genet 46:223-232 (2009).

Hastings PJ, Lupski JR, Rosenberg SM, Ira G: Mechanisms of change in gene copy number. Nat Rev Genet 10:551-564 (2009).

-Hochstenbach R, van Binsbergen E, Engelen J, Nieuwint A, Polstra A, et al: Array analysis and karyotyping: workflow consequences based on a retrospective study of 36,325 patients with idiopathic developmental delay in the Netherlands. Eur J Med Genet 52:161-169 (2009).

Hochstenbach R, Buizer-Voskamp JE, Vorstman JA, Ophoff RA: Genome arrays for the detection of copy number variations in idiopathic mental retardation, idiopathic generalized epilepsy and neuropsychiatric disorders: lessons for diagnostic workflow and research. Cytogenet Genome Res 135:174-202 (2011).

Ishmukhametova A, Chen JM, Bernard R, de Massy B, Baudat F, et al: Dissecting the structure and mechanism of a complex duplication-triplication rearrangement in the $D M D$ gene. Hum Mutat 34:1080-1084 (2013). Knight SJ, et al: A new chromosome 17q21.31 microdeletion syndrome associated with a common inversion polymorphism. Nat Genet 38:999-1001 (2006).

-Mefford HC, Sharp AJ, Baker C, Itsara A, Jiang Z, et al: Recurrent rearrangements of chromosome 1q21.1 and variable pediatric phenotypes. N Engl J Med 359:1685-1699 (2008).

Poot M, Eleveld MJ, van 't Slot R, Ploos van Amstel HK, Hochstenbach R: Recurrent copy number changes in mentally retarded children harbour genes involved in cellular localization and the glutamate receptor complex. Eur J Hum Genet 18:39-46 (2010).

- Poot M, van der Smagt JJ, Brilstra EH, Bourgeron $\mathrm{T}$ : Disentangling the myriad genomics of complex disorders, specifically focusing on autism, epilepsy, and schizophrenia. Cytogenet Genome Res 135:228-240 (2011).

- Sharp AJ, Cheng Z, Eichler EE: Structural variation of the human genome. Annu Rev Genomics Hum Genet 7:407-442 (2006a).

Sharp AJ, Hansen S, Selzer RR, Cheng Z, Regan R, et al: Discovery of previously unidentified genomic disorders from the duplication architecture of the human genome. Nat Genet 38: 1038-1042 (2006b).

-Ji Y, Eichler EE, Schwartz S, Nicholls RD: Structure of chromosomal duplicons and their role in mediating human genomic disorders. Genome Res 10:597-610 (2000).

Kidd JM, Cooper GM, Donahue WF, Hayden HS, Sampas N, et al: Mapping and sequencing of structural variation from eight human genomes. Nature 453:56-64 (2008).
Shimojima K, Mano T, Kashiwagi M, Tanabe T, Sugawara M, et al: Pelizaeus-Merzbacher disease caused by a duplication-inverted triplication-duplication in chromosomal segments including the PLP1 region. Eur J Med Genet 55:400-403 (2012).

Soler-Alfonso C, Carvalho CM, Ge J, Roney EK, Bader PI, et al: CHRNA7 triplication associated with cognitive impairment and neuropsychiatric phenotypes in a three-generation pedigree. Eur J Hum Genet 22:1071-1076 (2014). 